\title{
Symptoms of Depression and Disability among Rheumatoid Arthritis Patients
}

\section{Ebtsam Abd El Monim Mohamed ${ }^{1,}$ Sorayia Ramadan Abd-Elfatah ${ }^{2,}$ Gihan Omar $^{3}$, Amany Anter Mohammed ${ }^{4}$}

\author{
1Assist lecturer of psychiatric Mental Health Nursing, Faculty of Nursing, Minia University \\ 2Professor of Psychiatric Mental Health Nursing, Faculty of Nursing, Ain shams University \\ 3 Professors of Rheumatology and Rehabilitation, Faculty of Medicine-Minia University \\ 4Assist Professor of psychiatric Mental Health Nursing, Faculty of Nursing, Minia University
}

\begin{abstract}
Background Rheumatoid arthritis (RA) is a significant and serious public illness affecting peoples especially adults all over the world and emotional problems such as depressive symptoms are more common in patients with RA than in general population. Synovial inflammation, joint damage, degeneration of cartilage, bony destruction and limitation of physical functioning are the distinctive feature of RA that consequently leads to functional disability. This study aimed at assesses prevalence of symptoms of depression and disability among RA patients. Research Design: A descriptive correlational research design was utilized in this study. Study subjects: Established diagnosed 80 RA patients were included in the study. Two tools were used; Beck Depression Inventory (BDI) version I to assess symptoms of depression, and Health assessment questionnaire-disability index (HAQ-DI) to assess disease-related disability. Result: Majority of the participants were females with the age of (20-65) y. About two thirds of the studied sample had moderate depressive symptoms, while about three quarters of them have moderate level of disability. There was significant positive correlation between symptoms of depression and disability. Conclusion: More than three quarters of the studied sample had moderate to severe level of depressive symptoms and disability. Recommendation of the study: Frequent assessments of depressive symptoms and disability in RA patients.
\end{abstract} Key Word: Rheumatoid Arthritis (RA), Depression, Disability

\begin{abstract}
Introduction
Rheumatoid arthritis (RA) is a chronic systemic inflammatory autoimmune disease characterized by proliferative inflammation of synovial joints (Kuo et al., 2020). It is common among adults around the world with prevalence rate about $1 \%$ of general population and commonly starts between the ages of 30-50 years (Vallerand et al., 2019), the occurrence in Women is two to three times more than men. There is no definite cause of RA; it is thought to involve a variety of factors mainly genetic in addition to environmental factors. RA cannot be cured and its management aimed to achieving remission" few or no symptoms" and maintaining good quality of life (Arthritis Foundation., 2019). Depressive symptoms is known in the rheumatology field as 'comorbidity' of RA (Vallerand et al., 2019) that occurs in about $16.8(10-23 \%)$ of patients and this is considered greater than prevalence in general population
\end{abstract} (Alan et al., 2016).

Depressive symptoms in RA may occur as a result of pain and disability which associated with impaired activity, organ dysfunction and altered role performance (Cunha et al., 2016). Also, there is a great evidence that joint pain, fatigue and disability result in physical and psychological stress which lead to disturbance in balance of brain neurotransmitters and hormones like serotonin, norepinephrine and this lead to negative impact on mood, behavior and cognition, that finally increasing the risk of depression (Arthritis Foundation, 2016; Zelman, 2018). According to a different model, depression in RA occur as a result of chronic inflammation from pro-inflammatory cytokine present in RA (Arthritis Foundation., 2016), The presence of depression in the case of RA results in different problems more than the burden of the emotional problem alone (Dures et al., 2014). It is linked with higher incidence of cardiovascular problems, heart attack, suicidal ideation (Tektonidou et al., 2011) increase health service use, impaired quality of life and higher mortality (Matcham, et al., 2016*).
RA also, has a great negative effects on patient's quality-of-life (QoL), including physical, mental, social and occupational aspects (Matchamet al., 2014; Qorolli et al., 2019). Health-related quality of life (HRQL) involve physical, emotional, , social and particular feelings of wellbeing which represent the person's evaluation and response to his disease (Fontaine, 2011; Malm et al., 2017). RA is affecting quality of life directly and indirectly, and accounted as the major cause of health service consuming, the main cause of handicap, the first reason for impaired work productivity and early retirement. Pain and physical disability that present in RA accompanied with limited activity, organ deterioration, and impaired social and functional roles resulting, a negative effect on different aspects of patient life (Cunhaa et al., 2016). Poor quality of life in patients with RA is accompanied with increased healthcare resources usage and high risk of depression (Gaber et al., 2013; Gheita et al., 2014).

\section{Significance of the study}

Symptoms of depression has been listed as the most common symptom among psychological problems that negatively impacts patient's life and adversely affects multiple outcomes in RA beyond the burden of mental illness itself (Margaretten et al., 2011). Also RA has a considerable impact on patient's physical health and lead to great limitation in physical activity. Assessing both the physical and psychological symptoms of RA is very important to investigate the association between depression and disability, which considered a useful target for interventions aimed at improving physical and mental health status.

\section{Aim of the study}

This study aimed to assess prevalence of symptoms of depression and disability among RA patients.

\section{Subjects and Methods \\ Research design}

A descriptive correlational research design was utilized in this study. 


\section{Setting}

This study was conducted on a cohort of RA patients' recruited from out-patient clinic of Rheumatology and Rehabilitation Department at Minia university hospital. The Hospital serves as central hospital in Minia Governorate and its suburb areas.

\section{Subjects}

A purposive sample established diagnosed $80 \mathrm{RA}$ patients by rheumatologist which equal to $30 \%$ from total population size, and the total population size at a previous year was (270) (Mohamed., 2002; Roscoe., 1975).

\section{Inclusion Criteria \\ - Patients aged $\geq 18$ years (Adult RA). \\ - Disease duration $\geq$ one year. \\ - The patient should be adherent to follow up outpatient clinic.}

\section{Tools of Data Collection}

A well-designed questionnaire was used to collect the data of the recruited patients. Patient data were obtained from patient's record sheet in Rheumatology outpatient clinic and includes; demographic information: age, gender, educational level, marital status, occupation and clinical data (duration of illness).

\section{Tool (I): Beck Depression Inventory (BDI):}

(BDI) version I developed by Beck (1961), is a 21question multiple-choice self-report inventory measuring the severity of depressive symptoms The questionnaire contains 21 questions about how the subject has been feeling in the last week; each question has a set of at least four possible answer choices, ranging from 0 to 3 , indicating the severity of the symptom. Items 1 to 13 assess symptoms that are psychological in nature, while items 14 to 21 assess more physical symptoms (Beck. 1961). The questionnaire back translated to Arabic by Abdel- khalek, (1998), the translated questionnaire had shown a strong validity and reliability. Internal consistency showed a high value for standardized alpha (Cronbach's) $=0.98$ (Damati et al., 2000).

\section{Tool (II): The Health Assessment Questionnaire- Disability Index (HAQ-DI):}

Originally was developed in 1978 by James F. Fries and colleagues at Stanford University as a functional assessment tool measure disease-related disability and discomfort in patients with RA. The questionnaire contains 20 questions grouped into eight subscales as dressing and grooming, arising, eating, walking, hygiene, reach, grip and activities (Fries et al., 1982). The Arabic version of El- miedany was used. The translated questionnaire had shown a strong validity and reliability.

Internal consistency showed a high value for standardized alpha (Cronbach's): 0.979(El Miedany et al., 2003). The HAQ disability index was calculated as the sum of the scores for various subscales, divided by the number of subscales responded to, and results in a score between ( 0 and $3)$. Scores of 0 to 1 is generally represent mild to moderate difficulty, 1 to 2 represents moderate to severe disability, and 2 to 3 indicates severe to very severe disability (Fries et al., 1982).

\section{Pilot study}

Pilot Study was conducted on $10 \%$ from the total number which equal 8 patients of study sample to test the study process and to evaluate the efficiency, clarity, of tools that was used in the study. Subjects who participated in the pilot study were excluded from the actual study.

\section{Field work}

Each patient interviewed to collect the necessary data, the researcher went to Minia university hospital for two days per week (Sunday, and Wednesday from 9 am to $11 \mathrm{am}$ ). The questionnaires filled out by the researcher and also the researcher clarified the meaning of the questions to the patient facilitate understanding the meaning of the statements.

\section{Administrative Design}

An official letter was obtained from the dean of the Faculty of Nursing, Minia University, as well as the Head of rheumatology and rehabilitation department, asking for permission to collect data and carry out the program. Oral consent was obtained from the patients after explaining the nature and purpose of the study through direct personal communication to gain their acceptance and cooperation.

\section{Ethical Consideration}

A written initial approval obtained from the Research Ethical Committee of the Faculty of Nursing, Minia University, there was no risk for studied subject during application of this research, the study followed the common ethical rules in clinical research, and privacy was provided during data collection. Anonymity and confidentiality were assured through coding the data; and a patient had the right to refuse to participate in the study and without any rationale.

\section{Statistical Analysis}

Recorded data were analyzed using the statistical package for social sciences; version 24.0 Quantitative data were expressed as mean \pm standard deviation (SD). Qualitative data were expressed as frequency and percentage

Results

Table (1): Descriptive statistic of demographic and clinical data of the studied sample $(\mathbf{N}=\mathbf{8 0})$.

\begin{tabular}{|c|c|c|c|c|c|c|}
\hline & Variables & $\mathbf{N}$ & $\%$ & Mean \pm sd & Median & Range \\
\hline Age(y) & & & & $43.1 \pm 11.1$ & 42.5 & $20-65$ \\
\hline \multicolumn{7}{|l|}{ Sex } \\
\hline - & Male & 9 & $11.3 \%$ & & & \\
\hline 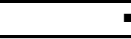 & Female & 71 & $88.7 \%$ & & & \\
\hline \multicolumn{7}{|c|}{ Marital state } \\
\hline 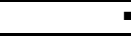 & single & 3 & $3.8 \%$ & & & \\
\hline - & Married & 59 & $73.8 \%$ & & & \\
\hline . & Divorced & 9 & $11.3 \%$ & & & \\
\hline - & Widow & 9 & $11.3 \%$ & & & \\
\hline Education & & & & & & \\
\hline
\end{tabular}


Minia Scientific Nursing Journal (Print) (ISSN 2537-012X) Vol. (7) No. (1) June 2020

\begin{tabular}{|c|c|c|c|c|c|c|}
\hline \multicolumn{2}{|r|}{ Variables } & $\mathbf{N}$ & $\%$ & \multirow[t]{2}{*}{ Mean $\pm \mathbf{s d}$} & \multirow[t]{2}{*}{ Median } & \multirow[t]{2}{*}{ Rang } \\
\hline - & Illiterate & 30 & $37.5 \%$ & & & \\
\hline - & Primary Education & 46 & $57.5 \%$ & & & \\
\hline - & Higher Education & 4 & $5 \%$ & & & \\
\hline \multicolumn{4}{|l|}{ Activity } & & & \\
\hline - & Non activity & 17 & $21.25 \%$ & & & \\
\hline 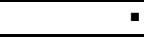 & Light activity & 16 & $20 \%$ & & & \\
\hline - & Moderate activity & 27 & $\underline{33.8 \%}$ & & & \\
\hline - & Heavy activity & 20 & $25 \%$ & & & \\
\hline \multicolumn{2}{|c|}{ Disease duration $(\mathbf{y})$} & & & $8.6 \pm 5.5$ & 8 & $1-20$ \\
\hline
\end{tabular}

Frequency $\%$

Mean \pm SD

Median

Table 1 showed the descriptive statistics of the 80 participants included in the study. In total, 71 (88.7) \% of participants were female, and the median age was 42.5 (20-65) y. The majority of participants were married 59 (73.8 \%) and $46(57.5 \%)$ of them were primary educated. About one third of the studied sample had moderate activity and the median disease duration was 8 (1-20) y.

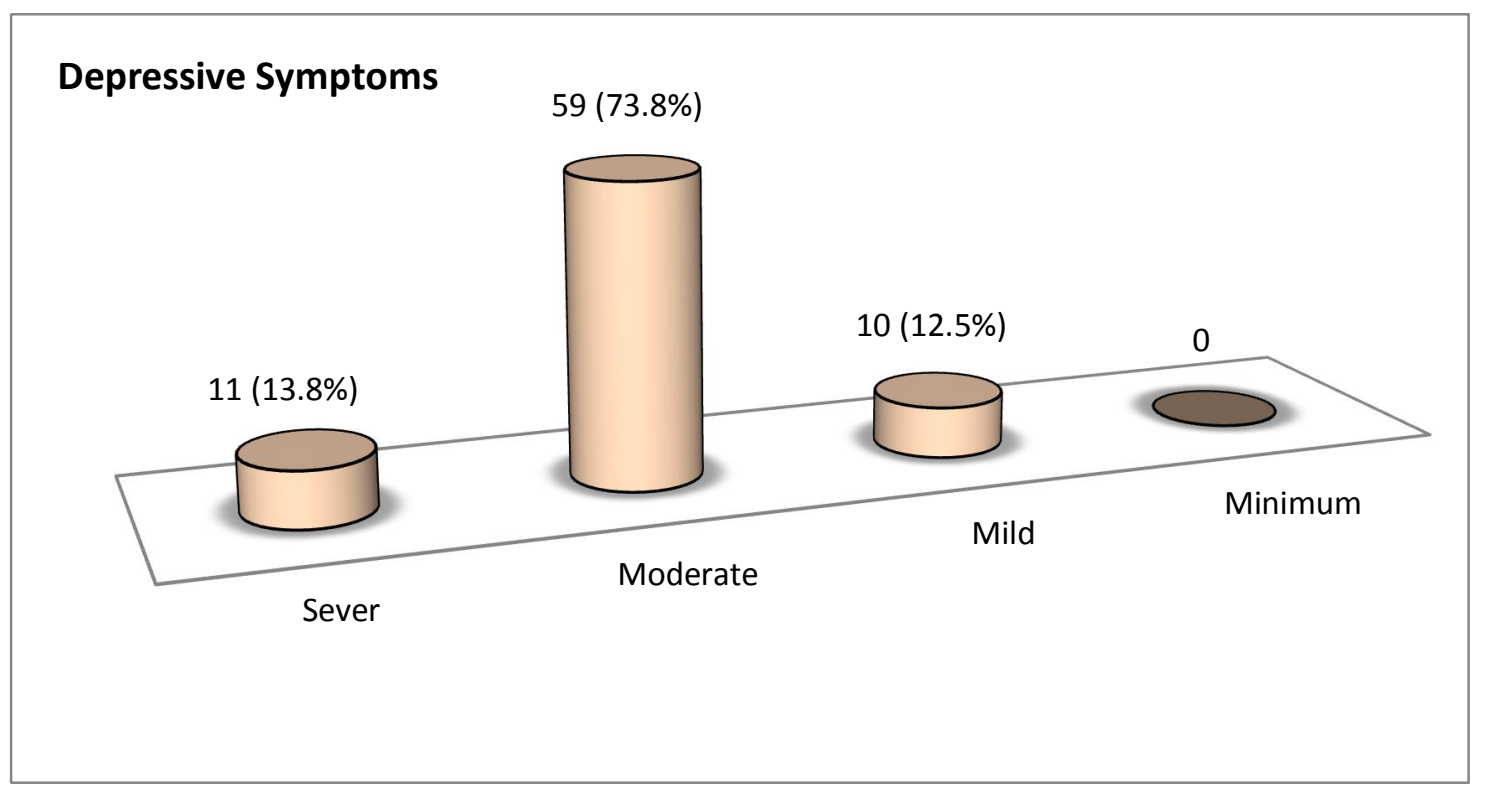

Figure (1): Frequency distribution of levels of symptom of Depression among the studied sample (N=80)

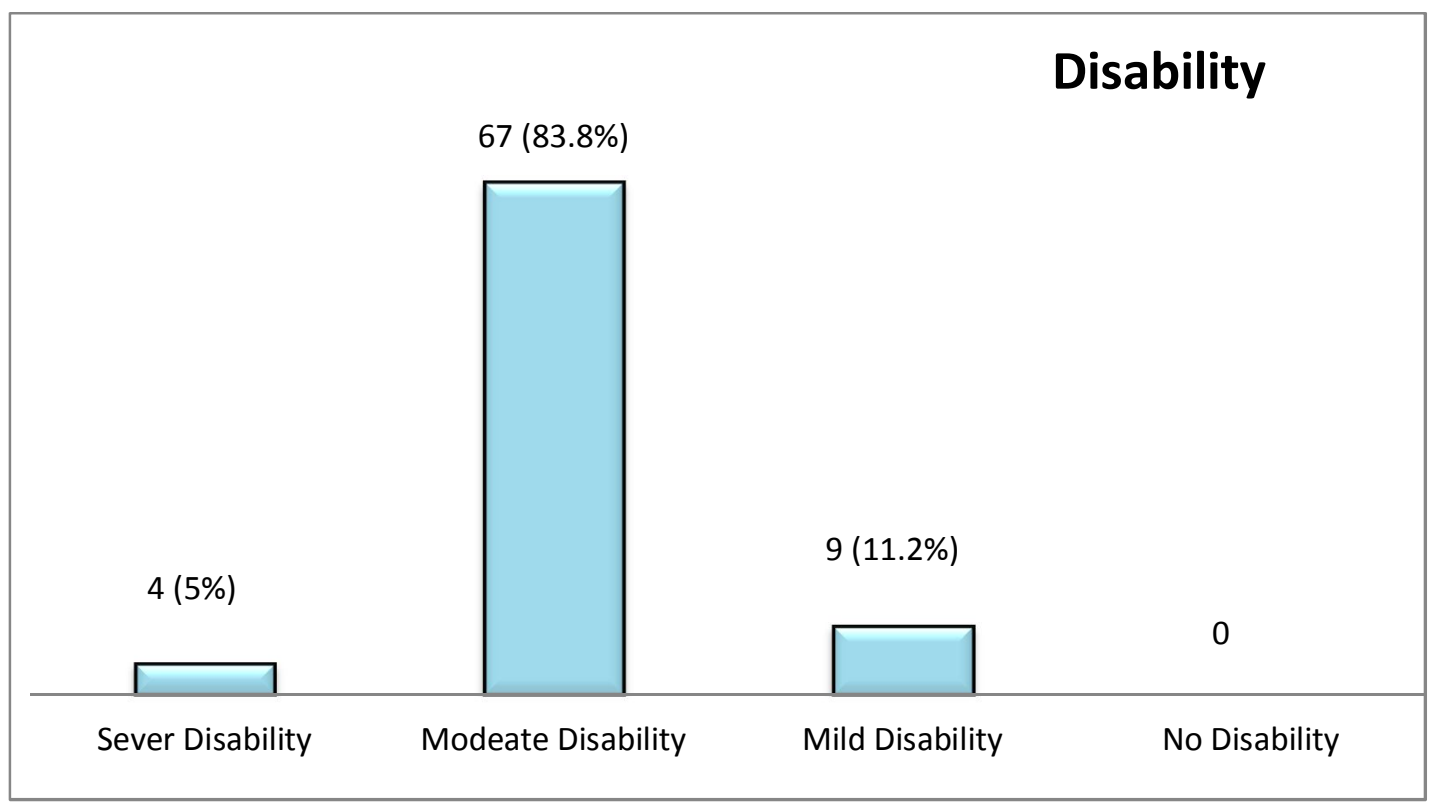

Figure (2): Frequency distribution of disability levels among the studied sample $(\mathbf{N}=80)$

Figure1, 2 showed the frequency distribution of depressive symptoms and disability levels. It can be noted from figure 1 that $59(73.8 \%)$ of the studied sample had moderate symptoms of depression, while figure 2 showed that $67(83.8 \%)$ had moderate level of disability. 
Minia Scientific Nursing Journal (Print) (ISSN 2537-012X) Vol. (7) No. (1) June 2020

Table (2). Comparison between levels of symptom of Depression relation to levels of disability among the studied sample $(\mathbf{N}=\mathbf{8 0})$.

\begin{tabular}{|c|c|c|c|c|c|c|c|c|c|c|c|c|}
\hline & & \multirow{3}{*}{$\begin{array}{c}\text { Minimum } \\
\mathbf{N} . \\
\mathbf{\%}\end{array}$} & \multicolumn{6}{|c|}{ Symptom of Depression } & \multirow{2}{*}{\multicolumn{2}{|c|}{ Total }} & $\mathrm{Ch}$ & $\begin{array}{l}\text { uare } \\
\text { t }\end{array}$ \\
\hline & & & \multicolumn{2}{|c|}{ Mild } & \multicolumn{2}{|c|}{ Moderate } & \multicolumn{2}{|c|}{ Sever } & & & $\mathbf{Y 2}$ & D \\
\hline & & & N. & $\%$ & N. & $\%$ & N. & $\%$ & N. & $\%$ & \multirow{6}{*}{2.02} & \multirow{6}{*}{0.04} \\
\hline \multirow{5}{*}{ Disability } & $\mathrm{NO}$ & 0 & \multicolumn{2}{|r|}{0} & \multicolumn{2}{|r|}{0} & \multicolumn{2}{|r|}{0} & \multicolumn{2}{|r|}{ 0 } & & \\
\hline & Mild & 0 & 1 & $1.3 \%$ & 6 & $7.5 \%$ & 6 & $2.5 \%$ & 9 & $11.2 \%$ & & \\
\hline & Moderate & 0 & 9 & $11.3 \%$ & 49 & $61.3 \%$ & 9 & $11.3 \%$ & 67 & $83.8 \%$ & & \\
\hline & Severe & 0 & 0 & 0 & 4 & $5 \%$ & 0 & 0 & 4 & $5 \%$ & & \\
\hline & Total & 0 & 10 & 12.5 & 59 & $73.8 \%$ & 11 & $13.8 \%$ & 80 & $100 \%$ & & \\
\hline
\end{tabular}

Table 2 revealed that there was statistically significant differences between levels of depressive symptoms in relation to levels of disability with $\mathrm{p}=.04$.

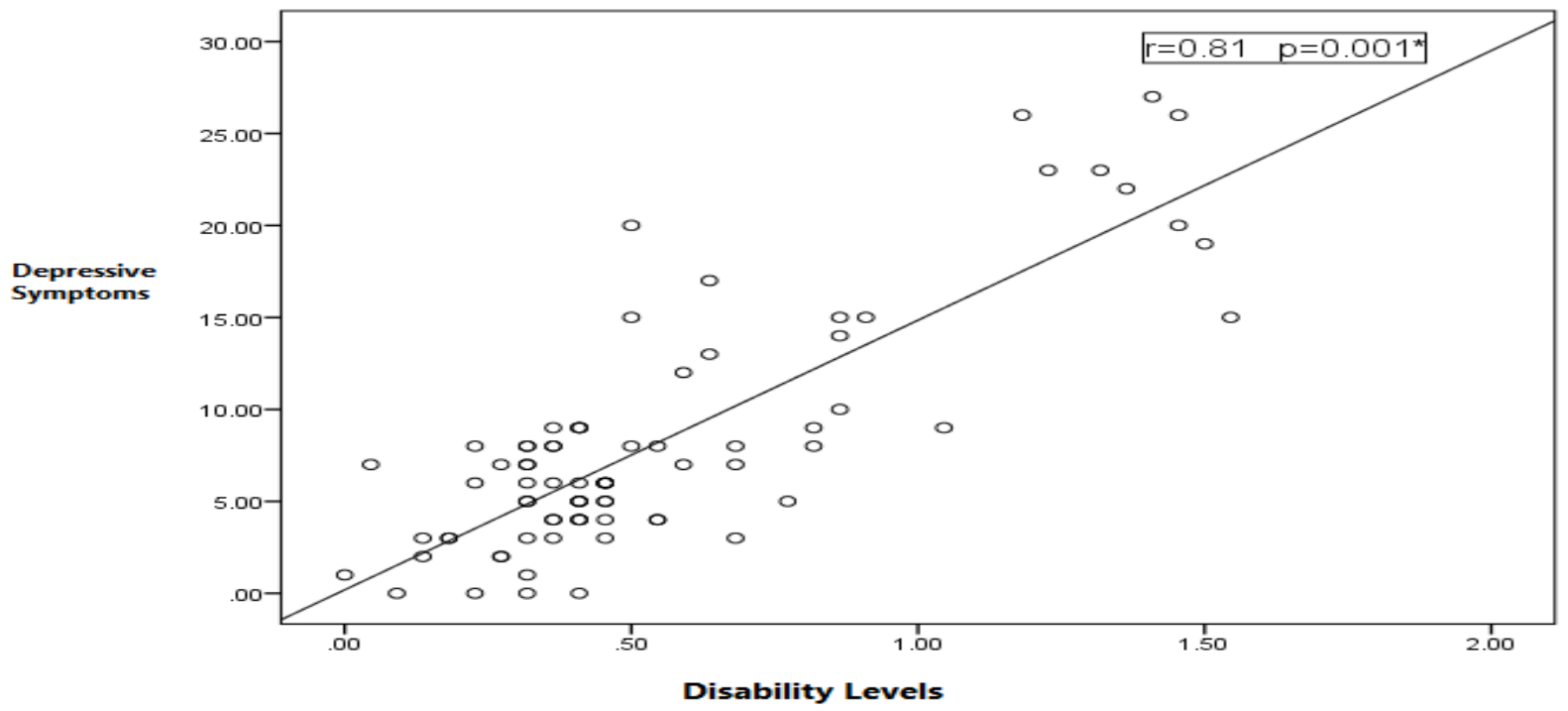

There was significant positive correlation between symptom of Depression and disability with total score $\mathrm{r}=.81$ at $\mathrm{P}=.0001$ which shown in Figure 3.

\section{Discussion}

The present study results revealed that female patients constituted more than three quarters of studied sample. This could be due to the fact that RA occurs in women three times more often than men (Cross et al., 2014) and that, traditionally; women seek health services more often than men (Barbosa et al., 2015). This finding was broadly consistent with the results of the study conducted in Egypt, Gamal et al. (2016) and Elsaman et al. (2017) who reported that majority of their studied sample were female.

As regard to age, the present study revealed that means age was $43.1 \pm 11.1 \mathrm{y}$, with range (20:65). This might be related to that most individuals' first experience RA between 30 and 50 years of age, but people of any age can be affected (Bautista et al., 2015). Also, the age of participants included in this study was detected to be more than 18 years old. This finding agrees with the study of Elsaman et al. (2017), who revealed that the mean age of the participants was $45 \pm 10.9$ y. Also, this finding was in congruent with Mahmoud et al. (2018) who found that mean age of $41.5 \pm$ 11.1 years.

The results concerning to marital status showed that about three quarters of the studied sample were married, this $P$ a g e $\mid 76$ might be due to that the health seeking behavior are more common among the married person due to the additional responsibilities and worries regarding inability to perform duties or loss of work as result of disease disability (Rezaei et al, 2014). This result was in agreed with the results of Hamed et al. (2017) and Rathbun et al. (2016), who found that married patients constituted the majority of the studied sample. This finding contradicted with the results of Barbosa et al. (2015) who reported that single patients constituted the majority of the studied sample.

In relation to education, results of the present study reported that about two third of the studied sample were primary educated; this might be a result of physical disability and symptoms of the disease that prevent completing the educational studies. This finding was in agreement with Gamal et al (2016) and Baloglu et al. (2015) who reported that the majority of their studied sample are less than high education level. This result contradicted with the result of Barbosa et al (2015) and Vinaccia et al (2017) who reported that most of the sample involved in their studies achieved higher educational level.

The current findings also revealed that more than one third of the studied sample had no and light activity. This

Ebtsam A., et al 
result might be due to physical disability which causes impairment in the ability to perform different activities. This result is consistent with the results of Gamal et al (2016) and (Rathbun et al. 2016) who reported that high percentage of the studied sample was not working. Moreover, Barbosa et al (2015) reported that $(43.3 \%)$ of his studied participants though in occupations with less physical work. As regard to duration of illness, the current results showed that mean duration $8.6 \pm$ $5.5 \mathrm{y}$ with range $(1: 20)$. This might be due to the chronicity of the disorder. This finding was broadly consistent with the results of Intriago et al (2019) who stated that Mean disease duration of the studied sample was $8.8 \pm 6.3$ years. The result was not in agreement with the findings of Gamal et al (2016) where the mean duration was $11.2 \pm 7.2$ years.

In the current study, more than three quarters of the studied sample had moderate and sever levels of depression, this high percentage could be attributed to several factors; the inflammatory nature of the disease, physical disability, pain, economic strains and lack of social support. RA also affects patients' physical identity, social role and self-image and change physical appearance to accommodate restrictions or tries to hide physical deformities (Matcham et al., 2016) which leading to a higher possibility of depression. From the researcher viewpoint, the majority of the current studied samples were females, and prior studies in RA have also found that female sex is associated with an increased incidence of depression (Lin et al., 2015; Wang at al., 2014). This result was in agreement with results of Cunha et al. (2016) who reported that the majority of people with RA had high and moderate levels of depression. This result was inconsistent with the results of Maldonado et al. (2017) who found that about half of the studied sample had mild depressive symptoms.

Results of the current study showed that more than three quarters of the studied sample had moderate to severe level of disability. This results might be related to the chronicity and inflammatory nature of the disease (Campos et al., 2013) where synovitis and joint damage cause impairment of physical function (Heinimann et al., 2018). From the researcher point of view this could be due to high level of depressive symptoms among the studied sample, and it is known that depressive symptoms negatively affect the health and functional status. This result was in agreement with the result of Barbosa et al.(2015) who mentioned that majority of his sample had moderate to severe disability. On the other hand, the results of wan et al.(2016) was inconsistent with the results of the present study, in which he found that majority of participants experienced mild to moderate functional disability. The inconsistency of findings may be related to sampling differences.

The result of current study revealed that there was significant positive correlation between depression and disability with total score. This could be attributed to the fact that performing a large number of activities is correlated with a good mental health and loss of valued activities beyond functional decline has been shown to lead to depression (Mostafa\& Radwan. 2013). A reduction of $10 \%$ in the ability to carry out activities of daily living causes a 7-fold increase in the risk of depression in the following years (Maldonado et al., 2017). This result was in the same line with the study of Mostafa\& Radwan.(2013) who revealed that a high positive correlation was found between HADS-D and HAQ scores. The study of Maldonado et al. (2017) demonstrated that patients with severe depression had the highest mean value of HAQ-DI and the patient who presented severe disability with HAQ-DI had high levels of depression.

\section{Conclusion}

More than three quarters of the studied sample had moderate to severe level of depression and disability and there was significant positive correlation between depression and disability.

\section{Recommendations}

- Frequent assessments of depressive symptoms and disability levels in RA patients.

- Planning a program that helps patients to adapt with symptoms of depression and managing disability.

\section{References}

1. Alan M, R., Leslie, R., George, W. (2016). A Prospective Evaluation of the Effects of Prevalent Depressive Symptoms on Disease Activity in Rheumatoid Arthritis Patients Treated With Biologic Response Modifiers. Clinical Therapeutics, Vol 38(7): 1759-72. C 2016ElsevierHSJournals.

2. Arthritis foundation. (2019). Your RA is in Remission! Now What? https://www.arthritis.org/healthwellness/treatment/treatment-plan/diseasemanagement/your-ra-is-in-remission!-now-what.

3. Arthritis Foundation. (2016): "The Arthritis-Depression Connection. The Arthritis Foundation, n.d. Web. https://www.arthritis.org/living-witharthritis/comorbidities/depression-and-arthritis/depressionrheumatoid-arthritis.php.

4. Baloglu H, Askin A, Yener M. (2015). Determination of the factors that affect health-related quality of life in patients with rheumatoid arthritis. Acta Medica Mediterranea 31(3):687-95.

5. Barbosa A F, Lima K C , Moacir de N L da Silva A S, et al. (2015). Quality of life of patients with rheumatoid arthritis under biological therapy. Rev. Assoc. Med. Bras. vol.61 no.2, p 126-31. http://dx.doi.org/10.1590/1806-9282.61.02.126.

6. Bautista, W, Fernandez, D., Jiménez, R., Cardozo, R., Marin, A., Soler, M. P., et al. (2015).Perfil epidemiológico de pacientescolombianos de arthritis reumatoide evaluados en unaclínica de especializada en atención integral. Reumatología Clínica. Doi. 10.1016/j.reuma.2015.11.009 Vol. 12. No. 6.pages 31318 DOI: 10.1016 / j.reuma. 2015.11.009.

7. Beck A. (1961). An inventory for measuring depression. Arch Gen Psychiatry; 4: 561-71.

8. Campos, Anna Paula Ribeiro, Silva, Cinthia Maria, Castro, Shamyr Sulyvam de, \& Graminha, Cristiane Vitaliano. (2013). Depression and quality of life in rheumatoid arthritis individuals and stable health individuals: a comparative study. Fisioterapia e Pesquisa, 20(4), 401407. https://dx.doi.org/10.1590/S180929502013000400016

9. Cross, M., Smith, E., Hoy, D., Carmona, L., Wolfe, F., Vos, T., et al. (2014). The global burden of rheumatoid arthritis: estimates from the Global Burden of Disease 2010 study. Ann. Rheum. Dis. 131, 6-1322.

10. Cunhaa, M., Ribeirob, A\& Andréc, S. (2016): Anxiety, depression and stress in patients with rheumatoid arthritis. Procedia - Social and Behavioral Sciences; 217, 337 -43.

11. Damati, Abdel ghaffar, Ahmed, Abdel Khalek., (2000). Beck Depression Inventory: Study on samples to Saudi Arabia. Message of education and psychology. No. 114, p..100.

12. Dures, E., Almeida, C., Caesley, J., et al. (2014). A Survey of Psychological Support Provision for People with 
Inflammatory Arthritis in Secondary Care in England. Musculoskeletal Care. Sep; 12(3): 173-81. doi: 10.1002/msc.1071. PMCID: PMC4282402. PMID: 24753071.

13. El Miedany Yasser M., Maha M. El Gaafary, Ihab Ahmed., (2003).Cross-cultural adaptation and validation of an Arabic Health Assessment Questionnaire for use in rheumatoid arthritis patients. Joint Bone Spine 70 ; 195202.

14. Elsaman A, Radwan A, Dahab MA, et al. (2017). AB0291 Epidemiology and comorbidity of rheumatoid arthritis in upper egypt, a hospital based study Annals of the Rheumatic Diseases;76: 1150.

15. Fontaine, K. (2011). Arthritis and Health-related Quality of Life. https://www.hopkinsarthritis.org/patientcorner/disease-management/quality-of-life-and-arthritis ./

16. Fries j, Spitz p, Young d. (1982). The dimensions of health outcomes: the health assessment questionnaire, disability and pain scales. J Rheumatol; 9: 789-93.

17. Gaber, W., Azkalany, G., Gheita, T., Mohey A, Sabry, R. (2013): Clinical significance of serum interleukin-6 and $174 \mathrm{G} / \mathrm{C}$ promoter polymorphism in rheumatoid arthritis patients. Egypt Rheumatol;35(2):107-13.

18. Gamal R.M, Mahran S, Abo El Fetoh N, and Janbi F, (2016): Quality of life assessment in Egyptian rheumatoid arthritis patients: Relation to clinical features and disease activity, The Egyptian Rheumatologist, 38(2):65-70.

19. Gheita, TA., Sayed, S., Gheita, HA., Kenawy, SA.(2014). Vitamin D status in rheumatoid arthritis patients: relation to clinical manifestations, disease activity, quality of life and fibromyalgia syndrome. Int $J$ Rheum Dis. http://dx.doi.org/10.1111/1756-185X.12426.

20. Hamed M S, El badawy A A, EL tokhy H M, Aboserea M M, Seliem H A. (2017). Changes in Health Related Quality of Life in Rheumatoid Arthritis Patients, Zagazig University Hospital; An interventional study. Journal of American Science; 13(5). doi:10.7537/marsjas130517.07.

21. Heinimann K, von Kempis J, Sauter R, Schiff M, SokkaIsler T, Schulze-Koops H et al. (2018). Long-term increase of radiographic damage and disability in patients with RA in relation to disease duration in the era of biologics. Results from the SCQM cohort. J Clin; 7:57.

22. Intriago $\mathrm{M}$, Maldonado $\mathrm{G}$, Cardenas $\mathrm{J}$, Rios $\mathrm{C}$. (2019).Quality of life in Ecuadorian patients with established rheumatoid arthritis. Open Access Rheumatology: Research and Reviews Volume 11:199205. DOI: 10.2147/OARRR.S216975.

23. Kuo, M.H., Tseng, C., Lee, C. et al. (2020). Moderate Risk of Hepatitis B Virus Reactivation in $\mathrm{HBsAg}-/ \mathrm{HBcAb}+$ Carriers Receiving Rituximab for Rheumatoid Arthritis. Sci Rep 10, 2456. https://doi.org/10.1038/s41598-02059406-4.

24. Lin, M, Guo, H, Lu, M, et al., (2015). Increased risk of depression in patients with rheumatoid arthritis: A sevenyear population-based cohort study. Clinics (São Paulo, Brazil), 70(2), 91-6.

25. Mahmoud G A., Rady H M., Mostafa A M. (2018). Cross cultural adaptation and validation of an Arabic version of selected PROMIS measures for use in rheumatoid arthritis patients. The Egyptian Rheumatologisthttps://doi.org/10.1016/j.ejr.2018.09.003.

26. Maldonado, G., Ríos, C., Paredes, C., Ferro, C., Intriago, MJ., Aguirre ,C., et al. (2017): Depression in rheumatoid arthritis. Rev Colomb Reumatol. Vol 24(2): 61-128 DOI: 10.1016 / j.rcreue.2017.07.001.

27. Malm, K., Bergman, S., Andersson, M. L., Bremander, A., \& Larsson, I. (2017). Quality of life in patients with established rheumatoid arthritis: A phenomenographic study. SAGE open medicine, 5, 2050312117713647. doi:10.1177/2050312117713647.

28. Margaretten, M., Julian, L., Katz, P., Yelin, E. (2011). Depression in patients with rheumatoid arthritis: description, causes and mechanisms. International journal of clinical rheumatology, 6(6), 617-23.

29. Matcham, F., Ali, S., Irving, K., Hotopf, M., \& Chalder, T. (2016). Are depression and anxiety associated with disease activity in rheumatoid arthritis? A prospective study. BMC musculoskeletal disorders, 17, 155. doi:10.1186/s12891016-1011-1.

30. Matcham, F., Scott, IC., Rayner, L., Hotopf, M., Kingsley, GH., Norton, S., Scott, DL., Steer, S. (2014). The impact of rheumatoid arthritis on quality-of-life assessed using the SF-36: a systematic review and meta-analysis. Semin Arthritis Rheum; 44(2):123-30.

31. Mohamed S M. (2002). Research methods in education and psychology. 1st ed. Dar el Masira, Jordan. ISBN"9957060732, 9789957060732.

32. Mostafa H, a Radwan R. (2013). The relationship between disease activity and depression in Egyptian patients with rheumatoid arthritis. The Egyptian Rheumatologist Volume 35, Issue 4, Pages 193-199.

33. Qorolli, M., Rexhepi, B., Rexhepi, S. et al. (2019). Rheumatol Int. https://doi.org/10.1007/s00296-019-04258z.

34. Rathbun A M, Harrold LR., Reed G W. (2016). A Prospective Evaluation of the Effects of Prevalent Depressive Symptoms on Disease Activity in Rheumatoid Arthritis Patients Treated With Biologic Response Modifiers. Clinical Therapeutics/Volume38.

35. Rezaei, F., Neshat, H., Taher, D., Molavi, H., et al. (2014). Depression and pain in patients with rheumatoid arthritis: Mediating role of illness perception. The Egyptian Rheumatologist (2014) 36, 57-64.

36. Roscoe, J.T. (1975). Fundamental Research Statistics for the Behavioral Science, International Series in Decision Process, 2nd Edition, Holt, Rinehart and Winston, Inc., New York.

37. Tektonidou, MG., Dasgupta, A., Ward, MM. (2011). Suicidal ideation among adults with arthritis: prevalence and subgroups at highest risk. Data from the 2007-2008 National Health and Nutrition Examination Survey. Arthritis Care Res. (Hoboken);63(9):1322-33.

38. Vallerand I A, Scott PB, Chery B. (2019). Depression and the risk of rheumatoid arthritis. Current Opinion in Rheumatology: Volume 31 - Issue 3 - p 279-84. doi: 10.1097/BOR.0000000000000597.

39. Vinaccia S -A, Quiceno J M, Lozano F, Romero S. (2017). Health-related quality of life, illness perception, happiness and negative emotions in rheumatoid arthritis patients. Acta Colombiana de Psicología, vol. 20, no. 1. DOI: 10.14718/ACP.2017.20.1.4

40. Wan S WI, He H-Gu, Mak A. (2016). Health-related quality of life and its predictors among patients with rheumatoid arthritis. Applied Nursing Research 30, 176183http://dx.doi.org/10.1016/j.apnr.2015.07.004

41. Wang, Chang, Hu, et al., (2014). Risk of Developing Depressive Disorders following Rheumatoid Arthritis: A Nationwide Population-Based Study. http://dx.doi.org/10.1371/journal.pone.0107791.

42. Zelman, D. (October 03, 2018): How to Manage Depression That Comes With RA. WebMD Medical Reference. https://www.webmd.com/rheumatoidarthritis/ra-fight-depression 